\title{
Is dengue and malaria co-infection more severe than single infections? A retrospective matched-pair study in French Guiana
}

Loïc Epelboin ${ }^{1,2,3^{*}}$, Matthieu Hanf ${ }^{1,2}$, Philippe Dussart ${ }^{4}$, Sihem Ouar-Epelboin ${ }^{1}$, Félix Djossou ${ }^{2,5}$, Mathieu Nacher ${ }^{1,2}$ and Bernard Carme $e^{1,2}$

\begin{abstract}
Background: Dengue and malaria are two major arthropod-borne infections in tropical areas, but dual infections were only described for the first time in 2005. Reports of these concomitant infections are scarce and there is no evidence of more severe clinical and biological pictures than single infections.

Methods: To compare co-infections to dengue alone and malaria alone, a retrospective matched-pair study was conducted between 2004 and 2010 among patients admitted in the emergency department of Cayenne hospital, French Guiana.

Results: 104 dengue and malaria co-infection cases were identified during the study period and 208 individuals were matched in two comparison groups: dengue alone and malaria alone. In bivariate analysis, co-infection clinical picture was more severe than separated infections, in particular using the severe malaria WHO criteria. In multivariate analysis, independent factors associated with co-infection versus dengue were: masculine gender, CRP level $>50 \mathrm{mg} / \mathrm{L}$, thrombocytopaenia $<5010^{9} / \mathrm{L}$, and low haematocrit $<36 \%$ and independent factors significantly associated with co-infections versus malaria were red cells transfusion, low haematocrit $<36 \%$, thrombocytopaenia $<5010^{9} / \mathrm{L}$ and low Plasmodium parasitic load $<0.001 \%$.
\end{abstract}

Conclusions: In the present study, dengue and malaria co-infection clinical picture seems to be more severe than single infections in French Guiana, with a greater risk of deep thrombocytopaenia and anaemia.

Keywords: Dengue, Malaria, French Guiana, Thrombocytopaenia, Case-control studies

\section{Background}

Dengue fever and malaria are the most common arthropod-borne diseases in humans and represent major public health problems. Dengue virus (family Flaviridae, genus Flavivirus) and Plasmodium parasites are widespread in American and Asian tropical regions and their endemic areas overlap extensively. Nevertheless, reports of malaria and dengue dual infection are scarce. Since the first case reported in 2005 [1], only case-reports and two descriptive studies have been published. They have been reported with

\footnotetext{
* Correspondence: epelboincrh@hotmail.fr

'CIC-EC Antilles Guyane CIE 802 Inserm, Centre Hospitalier Andrée Rosemon, Cayenne, French Guiana

${ }^{2}$ Research team EPaT EA 3593, University of French West Indies and French Guiana, Cayenne, French Guiana

Full list of author information is available at the end of the article
}

Plasmodium falciparum and/or Plasmodium vivax in India and Pakistan [2-5], Southeast Asia [6,7], French Guiana [8] and Brazil [9]. This phenomenon seems to be uncommon. In a study performed in Thailand among 194 patients with dengue, no co-infection with malaria was found [10], but in French Guiana, a retrospective study performed in 2004-2005 on 1,723 consecutive febrile emergency patients found 17 co-infections, including six acute concurrent infections (e.g. $1 \%$ of dengue and $4 \%$ of malaria cases) [8]. The influence of co-infections on severity is not straightforward, therefore, the aim of this study was to differentiate clinical and biological picture of co-infections from infections alone and determine whether patients infected by both malaria and dengue (MD) were more severe than either infection alone (respectively $M$ and $D$ ).

\section{Biomed Central}




\section{Methods}

\section{Study location}

French Guiana is a French Overseas territory located on the north-eastern coast of South America. About 90\% of its surface of $84,000 \mathrm{~km}^{2}$ is Amazonian rain forest; the remaining $10 \%$ in the north is a coastal plain where $90 \%$ of the 215,000 inhabitants live and Cayenne and surroundings contain almost $50 \%$ of the population in 2009 [11]. Malaria and dengue fever (DF) represent two major public health concerns in French Guiana. Malaria is endemic and the annual number of cases ranges from 3,200 to 4,700 [12]. Until 2006, P. vivax represented 50\% of annual cases. The current proportion of $P$. vivax malaria is $75 \%$, as in the rest of the Americas [12-14]. Since the first cases of DF were reported in French Guiana in 1943, an increase in the number of DF cases and DF outbreaks and the emergence of dengue hemorrhagic fever (DHF) have been observed [15]. All four dengue virus serotypes circulate in French Guiana. The last two mains epidemics occurred in 2006 and 2009, and dengue is currently endemic. Until 2005, dengue outbreaks were exclusively described on the coast. Since 2006, outbreaks of DF have been reported in interior villages where malaria is endemic [16].

\section{Study population}

A matched retrospective study was conducted comparing patients infected with concurrent malaria and dengue to patients with either infection alone. The study population included all patients admitted in the emergency department of Cayenne hospital, between June 2004 and February 2010. The diagnosis of dengue and malaria coinfection was made on the basis of concomitant biological diagnosis of dengue and malaria within seven days in patients with a compatible clinical picture. Two control groups were constituted: the group $M$ with positive biological diagnosis for malaria and negative for dengue, according to the criteria defined in the next paragraph, and the contrary for the group D. Control cases were matched on the date of biological diagnosis of infection.

Case definitions were based on compatible clinical history and biological diagnosis. Malaria diagnosis relied on the identification of haematozoa on a thin blood film and/ or on a thick blood film stained with Giemsa (group MD and $M$ ). The screening sensitivity was $\approx 6$ plasmodia $/ \mu \mathrm{L}$ (1/1,000 leukocytes). The asexual parasite load (PL) was classified in five classes: class 5: $>1.25 \%$; class $4: 0.125$ to $1.25 \%$; class 3 : $0.0125 \%$ to $0.125 \%$; class $2: 0.00125$ to $0.0125 \%$; and class $1: \leq 0.00125$. Malaria rapid diagnosis tests were not systematically performed on the study period. Due to the evolution of the techniques between 2004 and 2010, the laboratory diagnosis of dengue relied on different methods. Direct diagnosis was based on virus isolation, genome detection by Reverse TranscriptasePolymerase Chain Reaction (RT-PCR) or NS1 antigen detection introduced in 2006 in French Guiana. Indirect diagnosis was based on detection of specific anti-dengue IgM and/or IgA antibodies in patients' sera [17]. When NS1 antigen detection was available, RT-PCR, which allows serotype identification, was not systematically performed.

Concerning dengue definition (groups $\mathrm{MD}$ and $\mathrm{D}$ ), cases were separated in two groups: "confirmed acute dengue cases" (CADC) were defined by direct biological diagnosis (NS1 antigen and/or RT-PCR and/or virus isolation), IgM seroconversion (early serum sample negative for IgM but convalescent sample positive) or IgA antibodies detection. "Likely dengue cases" (LDC) were defined by IgM antibodies detection. Indeed, IgM appear between the $3^{\text {rd }}$ and $5^{\text {th }}$ day of fever but can persist for over three months and IgA appear concomitantly with IgM but does not persist longer than five to six weeks $[18,19]$. There was no discrimination between dengue primary infection and secondary infection, e.g., further infection(s) by dengue of a different serotype.

Covariates included, data collection and statistical analysis Patients' data, including socio-epidemiologic data, previous medical history, clinical symptoms, and biological results, were obtained from the computerized medical charts. Data were analysed using $\mathrm{R}$ version $2.10 .0^{\circledR}$ and the Epicalc ${ }^{\circledR}$ package.

The continuous variables of interest were categorized following the laboratory cut-off values, or published values. They generally were dichotomized because of the small sample size.

Two analyses were performed comparing separately $\mathrm{MD}$ to $\mathrm{D}$ and $\mathrm{MD}$ to $\mathrm{M}$. For categorical variables, a matched bivariate analysis using the Wald test was performed to identify factors associated with co-infections. Statistical significance was set at $\mathrm{p}<0.05$. Variables with a p-value $<0.2$ in bivariate analyses were entered into multivariate model to identify the factors independently associated with dengue-malaria co-infections. As bivariate analysis were made in an exploratory way and used as a selection criterion for inclusion in the final multivariate model $(\mathrm{p}<0.20)$, we did not judge as a necessity to adjust bivariate $\mathrm{p}$-values for multiple comparisons. Thus, bivariate p-values near to 0.05 must be relativized. To obtain more powerful models, and because of the missing data inherent to retrospective studies, variables obtained from anamnesis and clinical examination and variables with more than $5 \%$ of missing data were excluded from the model. Thus, conditional multivariate backward stepwise logistic regression estimated the adjusted odds ratio (OR) and the confidence intervals linked to co-infections. 


\section{Ethical considerations}

The retrospective use of anonymous patient files on the site of patient care is authorized by the French National Commission on Informatics and Liberties. All the data collected retrospectively were anonymized in a standardized case report form and in the database.

\section{Results}

\section{Cases description}

Between June 2004 and February 2010, 104 patients satisfied the criteria for MD (Figure 1). Consequently, 208 patients were matched in each comparison group. Among the 104 MD patients, 75 (72.1\%) were men and $11(10.6 \%)$ were 15 years-old or under. The mean age was 33.8 years (range: 6 months to 83 years). Forty-one (39.4\%) were considered as CADC and 63 (60.6\%) as LDC versus $150(72.1 \%)$ and 58 (27.9\%; $p<0.001)$ in the group D, respectively (Table 1 ). The dengue virus serotype could be identified for only 10 (9.6\%) of co-infected patients (DENV-1: 3 (30\%); DENV-2: 2 (20\%) and DENV-3: 5 (50\%)) and 91 in the control group (DENV-1: 25 (27.5\%); DENV-2: 25 (27.5\%); DENV-3: 28 (30.8\%) and DENV-4: 13 (14.2\%)). No significant difference was found in the proportion of $P$. vivax between the MD group and $M$ group: $P$. vivax (76.7\% vs. $68.1 \%$ respectively),
P. falciparum (20.4\% vs. $28 \%$ ) and association of $P$. vivax and P. falciparum (2.9\% vs. 3.9\%). Species identification was not possible in two patients because they had received anti-malarial treatment after positive rapid diagnostic testing in a health centre. A low PL (class 1 and 2) tended to be more frequent in the MD group than $\mathrm{M}$ group (p 0.08) (Table 2).

\section{Comparison of co-infection with dengue}

Clinical and biological pictures of co-infection cases were different from single infections and bivariate comparisons showed more differences between MD and D than between MD and M (Table 3). MD patients were more often adult men. A quarter of them reported having recently visited the forest (military, forest workers or gold miners) versus $3 \%$ in the $\mathrm{D}$ group. Patients from MD group resided more frequently far from the coast than $D$ patients and had a history of malaria and recent malaria attacks ( $<3$ months). The duration of fever was longer in MD patients and they were hospitalized more frequently than D patients, but hospitalization was not longer. More patients required a transfusion in the MD group. The clinical presentation in MD patients was generally more severe, with more fever above $40^{\circ} \mathrm{C}$, tachycardia, initial hypotension, nausea, vomiting and dehydration

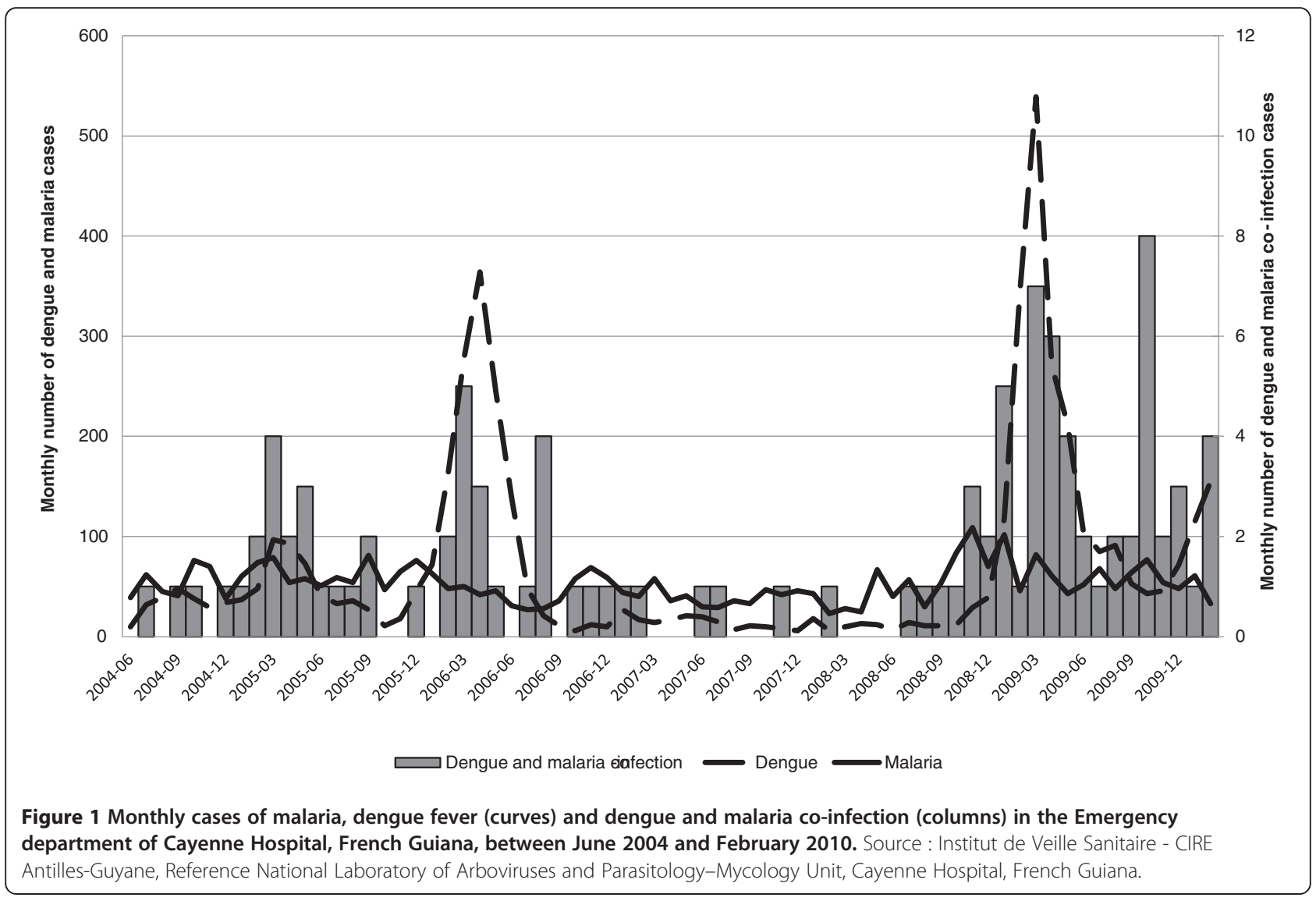


Table 1 Laboratory diagnosis of dengue infection in the co-infected group and in the single dengue infection group

\begin{tabular}{lccc}
\hline Dengue laboratory diagnosis & $\begin{array}{c}\text { Co-infection } \\
\mathbf{n}(\%)\end{array}$ & $\begin{array}{c}\text { Dengue } \\
\mathbf{n}(\%)\end{array}$ & Cases \\
\hline Cell culture virus isolation and/or & $9(8.7)$ & $56(26.9)$ & CADC $^{\S}$ \\
RT-PCR* & $11(10.6)$ & $84(40.4)$ & \\
NS1 antigen +/- lgM* & $14(13.5)$ & $9(4.3)$ & \\
IgM + lgA* & $7(6.7)$ & $1(0.5)$ & \\
IgM seroconversion & $63(60.6)$ & $58(27.9)$ & LDC $^{\S}$ \\
IgM & $\mathbf{1 0 4}$ & $\mathbf{2 0 8}$ & \\
Total & &
\end{tabular}

${ }^{*} R T-P C R$ Reverse transcriptase polymerase chain reaction, $\lg M$ Anti dengue immunoglobulin $\mathrm{M}$, IgA Anti dengue immunoglobulin $\mathrm{A}$.

$\S$ CADC Confirmed acute dengue cases, LDC Likely dengue cases.

than D patients. Furthermore, cases which fulfilled one or more of the WHO clinical and/or biological criteria for severe falciparum malaria [20] were more frequent in the MD group than in the D group $(\mathrm{p}<0.001)$. Increased $C$ - reactive protein (CRP), especially $>50 \mathrm{mg} / \mathrm{L}$, was significantly associated with MD co-infections $(p<0.001)$ relative to dengue alone. Retro-orbital pain, skin rash and ENT symptoms were significantly associated with D. Anaemia ( $p 0.02$ ), severe thrombocytopaenia ( $<<0.001$ ), and elevated bilirubin $(\mathrm{p}<0.001)$ were more frequent in MD patients. CADC diagnoses were significantly more frequent in the D group than in the MD group. Anaemia, severe thrombocytopaenia, male gender, high CRP level and LDC diagnosis were significantly associated with coinfection in multivariate analysis (Table 4).

\section{Comparison of co-infection with malaria}

No significant difference between MD and $M$ was found in terms of gender, age, place of residence and forestrelated activities (Table 2). A history of malaria was more frequent in the $\mathrm{M}$ group. The fever duration was longer in MD patients but not hospitalization. They received significantly more transfusions (p 0.02). Low blood pressure, signs of shock, pallor were significantly associated with the MD group. Anaemia and severe thrombocytopaenia were also significantly more frequent in the MD group. Cases which fulfilled one or more of the WHO criteria for severe falciparum malaria [20] were more frequent in the MD group than in the M group ( $p$ 0.007). Anaemia, severe thrombocytopaenia, low parasitaemia, and a high number of blood transfusions were independently associated with co-infections in multivariate analysis (Table 4).

\section{Discussion}

The unexceptional nature of the association of dengue and malaria is confirmed in French Guiana. In regions
Table 2 Matched bivariate analysis between co-infected patients and pure malaria infected patients

\begin{tabular}{|c|c|c|c|}
\hline Results n (\%) & $\begin{array}{l}\text { Co-infection } \\
(n=104)\end{array}$ & $\begin{array}{l}\text { Malaria } \\
(n=208)\end{array}$ & $\mathbf{p}^{* *}$ \\
\hline Males & $75(72.1)$ & $162(77.9)$ & 0.26 \\
\hline Children ( $<\mathbf{1 5}$ years-old) & $11(10.6)$ & $18(8.7)$ & 0.58 \\
\hline Journey in forest & $26(25)$ & $51(24.6)$ & 0.96 \\
\hline Inhabitant of the coast ${ }^{*}$ & $86(83.5)$ & $151(74.4)$ & 0.11 \\
\hline Long admission ( $\geq 2$ days) & $43(41.3)$ & $72(34.6)$ & 0.25 \\
\hline Admission & $37(35.6)$ & $69(33.2)$ & 0.67 \\
\hline Medical history of malaria & $52(50)$ & $115(62.8)$ & $0.02^{\S}$ \\
\hline $\begin{array}{l}\text { Time since last malaria } \\
\text { attack }<90 \text { days }\end{array}$ & 19 (55.9) & $49(51.6)$ & 0.91 \\
\hline Medical history of dengue & $3(3.4)$ & $16(9)$ & $0.08^{\$ \S}$ \\
\hline Duration of fever $>5$ days & $48(48.5)$ & $61(29.9)$ & $0.001^{\S}$ \\
\hline Red cells transfusion & $8(7.7)$ & $3(1.4)$ & $0.01^{\S}$ \\
\hline Tachycardia ( $>90$ bpm) & $79(79)$ & $165(82.1)$ & 0.64 \\
\hline Hypotension ( $<90 \mathrm{mmHg}$ ) & $10(10.4)$ & $7(3.6)$ & $0.01^{\S}$ \\
\hline Fever $\geq 40^{\circ} \mathrm{C}$ & $15(14.7)$ & $24(11.9)$ & 0.47 \\
\hline Retro-orbital pain & $4(3.9)$ & $10(5)$ & 0.61 \\
\hline Chills & $36(35.6)$ & $64(32.2)$ & 0.7 \\
\hline Hemorrhagic signs & $12(11.5)$ & $25(12.4)$ & 0.81 \\
\hline Shock signs & $7(6.8)$ & $8(4)$ & $0.16^{\S \S}$ \\
\hline Rash & $1(1)$ & $5(2.5)$ & 0.4 \\
\hline Nausea and / or vomiting & $58(56.9)$ & $93(45.8)$ & $0.06^{\S \S}$ \\
\hline Neurological disorders & $7(6.8)$ & $5(2.5)$ & $0.08^{\S \S}$ \\
\hline Dehydration & $7(7.4)$ & $10(5)$ & 0.37 \\
\hline Mucocutaneous pallor & $11(11.6)$ & $7(3.5)$ & $0.02^{\S}$ \\
\hline Splenomegaly & $9(12.3)$ & $23(18.3)$ & $0.08^{\S}$ \\
\hline Mucocutaneous jaundice & $9(8.7)$ & $9(4.3)$ & $0.14^{\S \S}$ \\
\hline ENT symptoms & $6(5.8)$ & $10(4.8)$ & 0.72 \\
\hline Severe "malaria" casest† & $34(32,7)$ & $39(18,7)$ & 0,007 \\
\hline $\begin{array}{l}\text { Low parasitaemia } \\
\text { (class }<\mathbf{3} \text { ) }\end{array}$ & $20(19.2)$ & $24(11.5)$ & $0.08^{\$ \S}$ \\
\hline $\begin{array}{l}\text { Mildly low hemoglobin } \\
\text { (<12 g/dl) }\end{array}$ & 37 (35.6) & $43(20.7)$ & $0.05^{\S \S}$ \\
\hline Low hematocrit (<36\%) & $43(41.3)$ & $49(23.6)$ & $0.002^{\S}$ \\
\hline $\begin{array}{l}\text { Deep thrombocytopenia } \\
\text { (<50 G/L) }\end{array}$ & $23(22.1)$ & $25(12)$ & $0.02^{\S}$ \\
\hline $\begin{array}{l}\text { Low prothrombin } \\
(<70 \%)\end{array}$ & $14(21.2)$ & $22(15.4)$ & 0.33 \\
\hline Hyponatremia $(<130)$ & $7(7.1)$ & $15(7.4)$ & 0.87 \\
\hline Hypokalemia (<3) & $6(6.1)$ & $15(7.4)$ & 0.67 \\
\hline $\begin{array}{l}\text { Elevated creatinin } \\
(>111 \mu \mathrm{mol} / \mathrm{L})\end{array}$ & $4(4)$ & $14(7)$ & 0.29 \\
\hline $\begin{array}{l}\text { Elevated bilirubin } \\
\text { (>50 } \mathrm{\mu mol} / \mathrm{L})\end{array}$ & $16(16.8)$ & $20(10.5)$ & 0.06 \\
\hline SGPT (>2 N) & $10(10.2)$ & $33(16.7)$ & $0.16^{\S}$ \\
\hline SGOT $>2 \mathrm{~N}$ & $13(13.3)$ & $23(11.6)$ & 0.66 \\
\hline
\end{tabular}


Table 2 Matched bivariate analysis between co-infected patients and pure malaria infected patients (Continued)

\begin{tabular}{clll}
\hline $\mathbf{C R P}<\mathbf{5}$ & $2(2)$ & $1(0.5)$ & 0.22 \\
$\mathbf{C R P} \mathbf{5}$ à $\mathbf{5 0}$ & $29(29)$ & $78(38)$ & - \\
$\mathbf{C R P}>\mathbf{5 0}$ & $69(69)$ & $126(61.5)$ & - \\
\hline
\end{tabular}

${ }^{*} p$ calculated with Wald test in matched bivariate analysis.

$\$$ Significant $p$-values $<0.05$ \$\$

$p$-values $<0.2$ included in the matched multivariate model.

bpm Beats per minute.

* Inhabitants of the coast are defined as people living in Cayenne, RémireMontjoly, Matoury Macouria, Kourou, Irakoubo or Mana.; Other people declared to live in Cacao, Roura, Montsinnéry-Tonnégrande, Régina, Saül, St-Elie, Saint Laurent du Maroni, Apatou, Maripasoula, Papaïchton, St George de l'Oyapock, Camopi or Trois-Sauts. 4 people came from France, 1 from the French Caribbean and 1 from French Polynesia.

${ }^{++}$WHO 2000 criteria for severe P. falciparum malaria

ENT Ear, Nose and Throat, SGPT Serum Glutamopyruvate Transferase, SGOT

Serum Glutamooxaloacetate Transférase, CRP C-reactive protein.

where these infections are transmitted in close proximity, the classical concept that malaria occurs in rural areas and dengue in urban areas may thus also be contradicted by facts in many countries and simultaneous infections may result from the overlap of the mosquito biotopes [16].

This study presented some minor biases. There were a higher number of cases based on the IgM detection in the MD group than in the $\mathrm{D}$ group. Co-infected patients with LDC were tested separately, so the association between MD and thrombocytopaenia, anaemia and frequent transfusions persisted in bivariate analysis, but not in multivariate analysis. However, when testing separately all patients with CADC diagnosis, no significant difference was found in bivariate and multivariate analysis which is probably due to the loss of power. The separation in two groups, LDC and CADC is arbitrary since the decision to perform the direct diagnosis relied on non verifiable information provided by patients on fever duration, a relatively unreliable answer given the frequent linguistic difficulties in FG. Studying confirmed acute cases alone was questionable, and the authors decided to study together likely and confirmed acute cases because it allowed a larger sample. Furthermore, associating likely cases would have minimized differences between the group MD and malaria alone because "real" associations would have been mixed with isolated malaria cases. It appears that co-infected patients consulted significantly later than the other groups, which may explains the predominance of IgM-diagnosed cases. However, almost all previous studies on dengue and malaria co-infections relied on IgM diagnosis [1,2,4-8,21]. Another hypothesis to explain the relatively high number of LDC in the study group is that malaria attack could have been triggered by dengue infection, especially as there is a majority of $P$. vivax infection, possibly relapses, which are coherent with the high frequency of malaria medical history, especially in the last three months in the
Table 3 Matched bivariate analysis between co-infected patients and pure dengue infected patients

\begin{tabular}{|c|c|c|c|}
\hline Results n (\%) & $\begin{array}{l}\text { Co-infection } \\
(n=104) N(\%)\end{array}$ & $\begin{array}{c}\text { Dengue } \\
(\mathrm{n}=\mathbf{2 0 8}) \mathrm{N}(\%)\end{array}$ & $p^{*}$ \\
\hline Males & $75(72.1)$ & $119(57.2)$ & $0.01^{\S}$ \\
\hline Children ( $<15$ years-old) & $11(10.6)$ & $49(23.6)$ & $0.008^{\S}$ \\
\hline Journey in forest & $26(25)$ & $7(3.4)$ & $<0.001^{\S}$ \\
\hline Living on the coast ${ }^{*}$ & $86(83.5)$ & $183(92.9)$ & $0.025^{\S}$ \\
\hline Long admission ( $\geq 2$ days) & $43(41.3)$ & $71(34.1)$ & 0.23 \\
\hline Admission & $37(35.6)$ & $45(21.6)$ & $0.01^{\S}$ \\
\hline Medical history of malaria & $52(50)$ & $21(10.2)$ & $<0.001^{\S}$ \\
\hline $\begin{array}{l}\text { Time since last malaria } \\
\text { attack }<\mathbf{9 0} \text { days }\end{array}$ & $15(44.1)$ & $0(0)$ & - \\
\hline Medical history of dengue & $3(3.4)$ & $5(2.7)$ & 0.64 \\
\hline Duration of fever $>5$ days & $48(48.5)$ & $33(16.3)$ & $<0.001^{\S}$ \\
\hline Red cells transfusion & $8(7.7)$ & $2(1)$ & $0.03^{\S}$ \\
\hline Tachycardia ( $>90$ bpm) & $79(79)$ & $128(64.6)$ & $0.03^{\S}$ \\
\hline Hypotension ( $<90 \mathrm{mmHg}$ ) & $10(10.4)$ & $3(1.8)$ & $0.02^{\S}$ \\
\hline Fever $\geq 40^{\circ} \mathrm{C}$ & $15(14.7)$ & $10(4.9)$ & $0.006^{\S}$ \\
\hline Retro-orbital pain & $4(3.9)$ & $26(12.6)$ & $0.01^{\S}$ \\
\hline Chills & $36(35.6)$ & $37(18)$ & $0.002^{\S}$ \\
\hline Hemorrhagic signs $^{\dagger}$ & $12(11.5)$ & $32(15.5)$ & 0.31 \\
\hline Shock signs & $7(6.8)$ & $5(2.4)$ & $0.06^{\S \S}$ \\
\hline Rash & $1(1)$ & $30(14.6)$ & $0.007^{\S}$ \\
\hline Neurological disorders & $7(6.8)$ & $8(3.9)$ & 0.28 \\
\hline Nausea and / or vomiting & $58(56.9)$ & $94(45.6)$ & $0.07^{\$ \S}$ \\
\hline Dehydration & $7(7.4)$ & $4(1.9)$ & $0.04^{\S}$ \\
\hline Mucocutaneous pallor & $11(11.6)$ & $3(1.5)$ & $0.003^{\S}$ \\
\hline Splenomegaly & $9(12.3)$ & $3(3.1)$ & $0.04^{\S}$ \\
\hline Jaundice & $9(8.7)$ & $6(2.9)$ & $0.03^{\S}$ \\
\hline ENT symptoms & $6(5.8)$ & $42(20.2)$ & $0.002^{\S}$ \\
\hline Severe "malaria" cases ${ }^{\dagger \dagger}$ & $34(32,7)$ & $33(15,9)$ & $<0,001$ \\
\hline $\begin{array}{l}\text { Confirmed acute } \\
\text { dengue cases }\end{array}$ & $41(39.4)$ & $150(72.1)$ & $<0.001^{\S}$ \\
\hline $\begin{array}{l}\text { Mildly low hemoglobin } \\
\text { (<12 g/dl) }\end{array}$ & $37(35.6)$ & $40(19.2)$ & $0.002^{\S}$ \\
\hline Low hematocrit (<36\%) & $43(41.3)$ & $34(16.4)$ & $<0.001^{\S}$ \\
\hline $\begin{array}{l}\text { Deep thrombocytopenia } \\
\text { (<50 G/L) }\end{array}$ & $23(22.1)$ & $6(2.9)$ & $<0.001^{\S}$ \\
\hline Low prothrombin $(<\mathbf{7 0} \%)$ & $14(21.2)$ & 19 (13.9) & $0.18^{\S \S}$ \\
\hline Hyponatremia $(<130)$ & $7(7.1)$ & $5(2.5)$ & $0.08^{\S \S}$ \\
\hline Hypokalemia (<3) & $6(6.1)$ & $3(1.5)$ & $0.04^{\S}$ \\
\hline $\begin{array}{l}\text { Elevated creatinin } \\
(>111 \mu \mathrm{mol} / \mathrm{L})\end{array}$ & $4(4)$ & $4(2)$ & 0.3 \\
\hline $\begin{array}{l}\text { Elevated bilirubin } \\
\text { ( }>50 \mu \mathrm{mol} / \mathrm{L})\end{array}$ & $16(16.8)$ & $3(1.6)$ & $<0.001^{\S}$ \\
\hline SGPT (>2 N) & $10(10.2)$ & $32(16)$ & 0.2 \\
\hline SGOT $>2 \mathrm{~N}$ & $13(13.3)$ & $41(20.5)$ & $0.16^{\S \S}$ \\
\hline CRP $<5$ & $2(2)$ & 73 (35.3) & $<0.001^{\S}$ \\
\hline
\end{tabular}


Table 3 Matched bivariate analysis between co-infected patients and pure dengue infected patients (Continued)

\begin{tabular}{lccc}
\hline CRP $\mathbf{5}$ à $\mathbf{5 0}$ & $29(29)$ & $115(55.6)$ & - \\
CRP $>\mathbf{5 0}$ & $69(69)$ & $19(9.2)$
\end{tabular}

* $p$ calculated with Wald test in matched bivariate analysis.

$\$$ Significant $p$-values $<0.05$.

$\$ \S p$-values $<0.2$ included in the matched multivariate model bpm Beats per minute.

* People living on the coast are defined as people living in Cayenne, Rémire-Montjoly, Matoury Macouria, Kourou, Irakoubo or Mana. ; Other people declared to live in Cacao, Roura, Montsinnéry-Tonnégrande, Régina, Saül, St-Elie, Saint Laurent du Maroni, Apatou, Maripasoula, Papaïchton, St George de l'Oyapock, Camopi or Trois-Sauts. 4 people came from France, 1 from the French Caribbean and 1 from French Polynesia.

'Hemorrhagic signs included purpura, gingival bleeding, epistaxis,

macroscopic hematuria, hematemesis, melena, rectal bleeding and hemoptysis.

"Signs of shock included systolic blood pressure $<90 \mathrm{mmHg}$ or not responding to IV fluids and with or without oliguria. ENT symptoms included

diagnoses of rhinitis, nasopharyngitis, pharyngitis, sinusitis and otitis.

${ }^{++}$WHO 2000 criteria for severe P. falciparum malaria [20].

ENT Ear, Nose and Throat, SGPT Serum Glutamopyruvate Transferase, SGOT

Serum Glutamooxaloacetate Transférase, CRP C-reactive protein.

MD [22]. As low parasitaemia was significantly more frequent in $\mathrm{MD}$ than in $\mathrm{M}$ group, another explanation could be the discovery of asymptomatic $P$. vivax infections in patients living in endemic areas, but this phenomenon has been barely described in the Amazonian region in Amerindian population, which is not the case here [23]. To ensure that low parasitaemia in the co-infection group did not result from asymptomatic infections, we tested MD patients with low parasitaemia versus $\mathrm{D}$ separately. The association between $\mathrm{MD}$ and thrombocytopaenia, anaemia, masculine gender, elevated CRP level, frequent transfusions persisted in bivariate analysis but not in multivariate analysis probably due to the loss of power. This result suggests that they were true MD co-infections with low parasite burdens.
The present study suggests an increased severity of the simultaneous infection compared to the isolated infections, which has only been hypothesized previously $[1,4]$, in particular with haematological consequences. However, severe malaria cases as defined by the WHO were more frequent in the MD group than in M and D separately in bivariate analysis [20]. Indeed because of insufficient power, $P$. vivax and $P$. falciparum malaria were pooled, which limits the study of $P$. falciparum severe malaria. Therefore, the biological influence of dengue virus, which affects the endothelium, a major protagonist of severe malaria pathophysiology, on the eventual severity of falciparum malaria, needs to be studied [24].

Co-infected patients presented deep thrombocytopenia more frequently than patients with single infections. Low platelets are common in dengue and malaria. In febrile patients living or returning from endemic areas, it is a good predictive factor of malaria $[25,26]$ and in case of negative malaria diagnosis it is a good predictive factor of dengue [25]. During malaria attack in adults, thrombocytopaenia is generally not considered to be a risk factor of haemorrhage and increased mortality [27]. Nevertheless, in non-immunized children with a malaria attack, a platelet count below $10010^{9} / \mathrm{L}$ has been demonstrated to be a predictive factor of mortality [28]. Furthermore, a study performed in France on 21,888 cases of imported P. falciparum malaria showed that thrombocytopaenia below 50 $10^{9} / \mathrm{L}$ was associated with an increased risk of mortality [29]. Considering dengue fever, high thrombocytopaenia is a known severity criterion and is linked to a higher mortality [30]. In the present study, severe thrombocytopaenia was not really accompanied with a recrudescence of haemorrhagic signs. No significant difference for the thrombocytopaenia between $P$. vivax and $P$. falciparum was

Table 4 Results of bivariate and multivariate analysis of co-infected group and single dengue infection and single malaria infection respectively

\begin{tabular}{|c|c|c|c|c|c|c|c|c|c|}
\hline & \multirow[t]{2}{*}{ Outcome } & \multicolumn{3}{|c|}{ Bivariate analysis } & \multicolumn{3}{|c|}{ Multivariate analysis } & \multirow{2}{*}{$\begin{array}{c}\text { Sensitivity } \\
\text { (\%) }\end{array}$} & \multirow{2}{*}{$\begin{array}{l}\text { Specificity } \\
\text { (\%) }\end{array}$} \\
\hline & & $\mathrm{OR}^{*}$ & $95 \% \mathrm{Cl}^{*}$ & $\mathrm{p}^{*}$ & $\mathrm{OR}^{* *}$ & $95 \% \mathrm{Cl}^{* *}$ & $\mathrm{p}^{* *}$ & & \\
\hline \multirow[t]{6}{*}{ Co-infection versus dengue } & Confirmed acute dengue cases & 5.3 & $2.9-9.7$ & $<0.001$ & 4.5 & $1.7-11.9$ & 0.003 & 79.1 & 52.1 \\
\hline & Males & 1.9 & $1.2-3.2$ & 0.01 & 3.4 & $1.1-10.3$ & 0.03 & 38.7 & 75.4 \\
\hline & Low hematocrit (<36\%) & 4.3 & $2.3-8.2$ & $<0.001$ & 8.4 & $2.2-32-5$ & 0.002 & 53.5 & 74.3 \\
\hline & Deep thrombocytopenia ( $\left.<50.10^{9} / L\right)$ & 13.8 & $4.1-46$ & $<0.001$ & 11.7 & $1.7-79.2$ & 0.01 & 79.3 & 71.4 \\
\hline & CRP 5 to $50 \mathrm{mg} / \mathrm{L}$ & 5.0 & $1.1-21.7$ & $<0.001$ & 5.3 & $0.9-29.3$ & 0.06 & - & - \\
\hline & CRP $>50 \mathrm{mg} / \mathrm{L}$ & 75.4 & $16-356.7$ & $<0.001$ & 74.4 & $12.2-453.3$ & $<0.001$ & 78.4 & 85.8 \\
\hline \multirow[t]{4}{*}{ Co-infection versus malaria } & Red cells transfusion & 7.3 & $1.5-34.7$ & 0.01 & 5.3 & $1.04-26.7$ & 0.04 & 72.7 & 68.1 \\
\hline & Low hematocrit (<36\%) & 2.2 & $1.3-3.6$ & 0.002 & 2 & $1.2-3.5$ & 0.009 & 46.0 & 72.6 \\
\hline & Deep thrombocytopenia ( $\left.<50.10^{9} / L\right)$ & 2.2 & $1.1-4.1$ & 0.02 & 2.1 & $1.02-4.1$ & 0.04 & 47.9 & 69.3 \\
\hline & Low parasitic load (class $<3$ ) & 1.8 & $0.9-3.3$ & 0.08 & 2.2 & $1.08-4.3$ & 0.03 & 45.4 & 68.6 \\
\hline
\end{tabular}

* Odds ratio (OR) and $95 \%$ confidence interval $(95 \% \mathrm{Cl})$ and $\mathrm{p}$ calculated by matched bivariate analysis.

** Odds ratio and $95 \%$ confidence interval and $\mathrm{p}$ calculated by matched multivariate analysis.

CRP C-reactive protein. 
observed. During malaria attacks, thrombocytopaenia generally worsens linearly with the increase of PL. This relationship did not clearly appear in patients co-infected with dengue so it is notable that deep thrombocytopaenia apparently occurred even with low parasite loads when associated with dengue virus.

Anaemia was more frequent in patients with dual infection. There was a convergence of indirect signs, such as pallor and transfusion need and elevated total bilirubin, probably in relation to increased haemolysis. Anaemia is a classical symptom of malaria but it is barely described in dengue fever. Indeed, elevated haematocrit is found in the severe dengue fever cases, resulting in plasma leakage syndrome [30]. The study performed on 21,888 cases of imported P. falciparum, showed that haemoglobin $<8 \mathrm{~g} / \mathrm{dL}$ was an independent predictive factor of mortality [29].

\section{Conclusions}

In the present study, concurrent dengue and malaria infection tends to be more severe than single infections notably for haematologic abnormalities, such as thrombocytopaenia and anaemia, known risk factors of severe dengue fever and/or malaria. However, whether this increased severity results from longer evolution duration or increased virulence or both remains to be determined. The study was retrospective so the results should be interpreted with caution. Whether prospective studies with homogeneous biological diagnosis methods and patient groups would be necessary to confirm the greatest severity of co-infection, the feasibility of such a study is questionable because of the very low prevalence of dual infection. The current evolution of these two mosquitoborne infections suggests that co-infections could become a medical problem. Since the biological and clinical characteristics of dengue and malaria are very similar, all clinicians treating patients in or returning from endemic areas should systematically order examinations for both diagnoses, even if one or the other is positive.

\footnotetext{
Abbreviations

95 Cl: 95\% Confidence interval; CADC: Confirmed acute dengue cases; CRP: C-reactive protein; D: Dengue fever group; DF: Dengue fever; DHF: Dengue haemorrhagic fever; ENT: Ear, nose and throat; Ig: Immunoglobulin; IV: Intravenous; LDC: Likely dengue cases; M: Malaria group; MD: Malaria and dengue co-infection group; OR: Odds ratio; PL: Parasite load (PL); RT-PCR: Reverse transcriptase-polymerase chain reaction (RT-PCR); SGOT: Serum glutamooxaloacetate transférase; SGPT: Serum glutamopyruvate transferase; WHO: World health organization.
}

\section{Competing interests}

The authors declare no competing interests.

\section{Acknowledgments}

The authors thank Dr. Brigitte Moreau and Dr. Stephan Gonon, respectively from the bacteriology laboratory and form the emergency department of Centre Hospitalier Andrée Rosemon, Cayenne, French Guiana and Luisiane Carvalho, from the Institut de Veille Sanitaire, Cayenne, French Guiana for their help in the acquisition of data.

\section{Author details}

'CIC-EC Antilles Guyane CIE 802 Inserm, Centre Hospitalier Andrée Rosemon, Cayenne, French Guiana. ${ }^{2}$ Research team EPaT EA 3593, University of French West Indies and French Guiana, Cayenne, French Guiana. ${ }^{3}$ Service de

Maladies Infectieuses et Tropicales, Centre Hospitalier Pitié-Salpêtrière, 47-83 bd de l'Hôpital, 75013, Paris, France. ${ }^{4}$ Centre National de Référence des Arboviroses, Institut Pasteur de Guyane, Cayenne, French Guiana. ${ }^{5}$ Infectious and Tropical Diseases Department, Centre Hospitalier Andrée Rosemon, Cayenne, French Guiana.

\section{Authors' contributions}

LE participated in the design of the study, performed the statistical analysis, contributed to the analysis and interpretation of data and drafted the manuscript. $\mathrm{MH}$ performed the statistical analysis and contributed to the analysis and interpretation of data. PD carried out the the immunoassays and the RT-PCR, contributed to the analysis and interpretation of data and helped to draft the manuscript SOE contributed to conception of the study and the acquisition of data. FD conceived of the study and contributed to the analysis and interpretation of data and helped to draft the manuscript. MN conceived of the study and contributed to the analysis and interpretation of data and helped to draft the manuscript. BC conceived the study and contributed to the analysis and interpretation of data and helped to draft the manuscript. All authors read and approved the final manuscript.

Received: 11 January 2012 Accepted: 1 May 2012

Published: 1 May 2012

\section{References}

1. Charrel RN, Brouqui P, Foucault $C$, de Lamballerie $X$ : Concurrent dengue and malaria. Emerg Infect Dis 2005, 11:1153-1154.

2. Arya CS, Mehta KL, Agarwal N, Agarwal BK, Mathai G, Moondhara A: Episodes of concurrent dengue and malaria. Dengue Bulletin 2005, 29:208-209.

3. Deresinski S: Concurrent Plasmodium vivax malaria and dengue. Emerg Infect Dis 1802, 2006:12.

4. Abbasi A, Butt N, Sheikh QH, Bhutto AR, Munir SM, Ahmed SM: Clinical features, diagnostic techniques and management of dual dengue and malaria infection. J Coll Physicians Surg Pak 2009, 19:25-29.

5. Ali N, Nadeem A, Anwar M, Tariq WU, Chotani RA: Dengue fever in malaria endemic areas. J Coll Physicians Surg Pak 2006, 16:340-342.

6. Ward DI: A case of fatal Plasmodium falciparum malaria complicated by acute dengue fever in East Timor. Am J Trop Med Hyg 2006, 75:182-185.

7. Thangaratham PS, Jeevan MK, Rajendran R, Samuel PP, Tyagi BK: Dual infection by dengue virus and Plasmodium vivax in Alappuzha District, Kerala, India. Jpn J Infect Dis 2006, 59:211-212.

8. Carme B, Matheus S, Donutil G, Raulin O, Nacher M, Morvan J: Concurrent dengue and malaria in Cayenne Hospital, French Guiana. Emerg Infect Dis 2009, 15:668-671.

9. dos Santos Santana V, Lavezzo LC, Mondini A, Terzian AC, Bronzoni RV, Rossit AR, Machado RL, Rahal P, Nogueira MC, Nogueira ML: Concurrent Dengue and malaria in the Amazon region. Rev Soc Bras Med Trop 2010, 43:508-511.

10. Singhsilarak T, Phongtananant S, Jenjittikul M, Watt G, Tangpakdee N, Popak N, Chalermrut K, Looareesuwan S: Possible acute coinfections in Thai malaria patients. Southeast Asian J Trop Med Public Health 2006, 37:1-4.

11. Populations légales en vigueur à compter du 1er janvier 2010 - Guyane - 973. [http://www.insee.fr].

12. Carme B: Substantial increase of malaria in inland areas of eastern French Guiana. Trop Med Int Health 2005, 10:154-159.

13. Carme B, Ardillon V, Girod R, Grenier C, Joubert M, Djossou F, Ravachol F: Situation épidémiologique du paludisme en Guyane. Med Trop (Mars) 2009, 69:19-25.

14. WHO: World Malaria Report. Geneva: World Health Organization; 2010:1-238.

15. Reynes JM: La dengue en Guyane Francaise. Historique et actualites. Bull Soc Pathol Exot 1996, 89:98-100.

16. Meynard JB, Ardillon V, Venturin C, Ravachol F, Basurko C, Matheus S, Gaborit P, Grenier C, Dussart P, Quenel P: First description of a dengue fever outbreak in the interior of French Guiana, February 2006. Eur J Public Health 2009, 19:183-188.

17. Dussart P, Petit L, Labeau B, Bremand L, Leduc A, Moua D, Matheus S, Baril L: Evaluation of two new commercial tests for the diagnosis of acute 
dengue virus infection using NS1 antigen detection in human serum. PLoS Negl Trop Dis 2008, 2:e280.

18. Balmaseda A, Guzman MG, Hammond S, Robleto G, Flores C, Tellez Y, Videa E, Saborio S, Perez L, Sandoval E, Rodriguez Y, Harris E: Diagnosis of dengue virus infection by detection of specific immunoglobulin $\mathrm{M}(\mathrm{IgM})$ and $\lg \mathrm{A}$ antibodies in serum and saliva. Clin Diagn Lab Immunol 2003, 10:317-322.

19. Talarmin A, Labeau B, Lelarge J, Sarthou JL: Immunoglobulin A-specific capture enzyme-linked immunosorbent assay for diagnosis of dengue fever. J Clin Microbiol 1998, 36:1189-1192.

20. World Health Organization (WHO): Severe falciparum malaria. World Health Organization, Communicable Diseases Cluster. Trans R Soc Trop Med Hyg 2000, 94(Suppl 1):1-90.

21. Kaushik RM, Varma A, Kaushik R, Gaur KJ: Concurrent dengue and malaria due to Plasmodium falciparum and P. vivax. Trans R Soc Trop Med Hyg 2007, 101:1048-1050.

22. Hanf M, Stephani A, Basurko C, Nacher M, Carme B: Determination of the Plasmodium vivax relapse pattern in Camopi, French Guiana. Malar J 2009, 8:278.

23. Alves FP, Durlacher RR, Menezes MJ, Krieger H, Silva LH, Camargo EP: High prevalence of asymptomatic Plasmodium vivax and Plasmodium falciparum infections in native Amazonian populations. Am J Trop Med Hyg 2002, 66:641-648.

24. Basu A, Chaturvedi UC: Vascular endothelium: the battlefield of dengue viruses. FEMS Immunol Med Microbiol 2008, 53:287-299.

25. Carme B, Sobesky M, Biard MH, Cotellon P, Aznar C, Fontanella JM: Nonspecific alert system for dengue epidemic outbreaks in areas of endemic malaria. A hospital-based evaluation in Cayenne (French Guiana). Epidemiol Infect 2003, 130:93-100.

26. Ansart $\mathrm{S}$, Perez $\mathrm{L}$, Thellier M, Danis M, Bricaire F, Caumes E: Predictive factors of imported malaria in 272 febrile returning travelers seen as outpatients. J Travel Med 2010, 17:124-129.

27. WHO: Guidelines for the treatment of malaria. Secondth edition. Geneva: World Health Organization Press; 2010:1-196.

28. Gerardin P, Rogier C, Ka AS, Jouvencel P, Brousse V, Imbert P: Prognostic value of thrombocytopenia in African children with falciparum malaria. Am J Trop Med Hyg 2002, 66:686-691.

29. Legros F, Bouchaud O, Ancelle T, Arnaud A, Cojean S, Le Bras J, Danis M, Fontanet A, Durand R: Risk factors for imported fatal Plasmodium falciparum malaria, France, 1996-2003. Emerg Infect Dis 2007, 13:883-888.

30. WHO: Dengue: guidelines for diagnosis, treatment, prevention and control. In World Health Organization and the Special Programme for Research and Training in Tropical Diseases (TDR). Geneva 2009:160.

doi:10.1186/1475-2875-11-142

Cite this article as: Epelboin et al:: Is dengue and malaria co-infection more severe than single infections? A retrospective matched-pair study in French Guiana. Malaria Journal 2012 11:142.

\section{Submit your next manuscript to BioMed Central and take full advantage of:}

- Convenient online submission

- Thorough peer review

- No space constraints or color figure charges

- Immediate publication on acceptance

- Inclusion in PubMed, CAS, Scopus and Google Scholar

- Research which is freely available for redistribution

Submit your manuscript at www.biomedcentral.com/submit

() BioMed Central 